Article

\title{
Experiment and Simulation Investigation on the Characteristics of Diesel Spray Impingement Based on Droplet Impact Phenomenon
}

\author{
Yongfeng Liu ${ }^{1}$, Qi Xiang ${ }^{1}$, Zhijun $\mathrm{Li}^{2, *}$, Shengzhuo Yao ${ }^{1}$, Xingyu Liang ${ }^{2}$ and Fang Wang ${ }^{1}$ \\ 1 Beijing Key Laboratory of Performance Guarantee on Urban Rail Transit Vehicles, \\ School of Mechanical-Electronic and Vehicle Engineering, Beijing University of Civil Engineering and \\ Architecture, Beijing 100044, China; liuyongfeng@bucea.edu.cn (Y.L.); xiangqi@stu.bucea.edu.cn (Q.X.); \\ yaoshengzhuo@bucea.edu.cn (S.Y.); wangfang@bucea.edu.cn (F.W.) \\ 2 State Key Laboratory of Engines, Tianjin University, Tianjin 300072, China; 1xy@tju.edu.cn \\ * Correspondence: lizhijundd@163.com; Tel.: +86-139-2057-8528
}

Received: 9 February 2018; Accepted: 2 March 2018; Published: 6 March 2018

\begin{abstract}
In order to study the characteristics of diesel spray impinging in small-size internal combustion (IC) engine, the laboratorial platform of spray impingement is used to visualize the droplet impact phenomenon. A high-speed camera is used to record the whole process of the spray. An experimental research is accomplished under the impingement phenomenon of diesel spray on the wall with a fixed injection volume of $25 \mathrm{mg}$, injection pressure of $40 \mathrm{MPa}$, wall-injector distance of $40 \mathrm{~mm}$ and orifice diameter of $0.26 \mathrm{~mm}$. The computational fluid dynamics (CFD) simulation is carried out and the turbulence kinetic energy (TKE) distribution diagram is obtained. The results show that the maximum spray radius is $29.3 \mathrm{~mm}$ and maximum spray height is $10.2 \mathrm{~mm}$ at $2.8 \mathrm{~ms}$. The spray impingement phenomenon presents the "blanket" shape. The simulation results are similar to the experimental results with the average error of the spray height within $3 \%$.
\end{abstract}

Keywords: diesel; impinging; spray characteristics; turbulence kinetic energy

\section{Introduction}

Light weight, high thermal efficiency, wide power range and compact structure is the characteristic of diesel engine. With vehicle weight reduction, the volume of the diesel engine has been reduced gradually in recent years, resulting in the spray penetration was short and the phenomenon of diesel spray came into collision with piston or cylinder wall occurring during fuel injection. After spray hitting the wall, the spray radius and height is changed, which will affect the mixing of fuel and air, and further affect the engine performance and exhaust particulate emissions. Therefore, it is significant to study the phenomenon of spray impingement on diesel engine [1-5].

The researches on spray characteristics were mainly based on the environmental density, the oil injection pressure and the angle of collision. Environmental density refers to the quality of unit volume air under certain temperature and pressure. Mao et al. $[6,7]$ studied the characteristics of diesel spray wall collision by quantitative analysis. Put forward the conclusions that spray radius decreases and spray height increases with the increase of environmental density. Wang et al. [8] studied the characteristics of diesel spray with high injection pressure by numerical simulation. Posed the conclusions that little effect on the volume of diesel spray and entrainment air quality but great effect on crushing rate by the injection pressure at low back pressure. Wei Du et al. [9] studied the effect of injection pressure on the spray characteristics of diesel by experiment. It was concluded that the effect of injection pressure on the liquid phase spray cone angle was minimal and the higher injection pressure caused higher vapor phase spray penetration rate. Yoshio Zama et al. [10] conducted 
experiments, went into the effects of ambient density, injection pressure and impact angle on the flow characteristics of impinging diesel spray. They concluded that the average peak velocity was positively correlated with the spray center velocity. R. payri et al. [11] studied the effect of nozzle inclination angle on spray characteristics by experiments and concluded that the lower angle of inlet hole was favorable for faster jet penetration. Enzhe Song et al. [12] did experimental research, investigated on the effect of shock wave, it was found that shock waves have a positive effect on nozzle penetration and air quality. However, they inhibit the radial development of spray. The researchers not only studied the spray characteristics of biodiesel, but also analyzed the spray characteristics of methanol diesel. Yu Shenghao et al. [13] compared the characteristics of diesel and biodiesel by theoretical and experimental comparison, concluded that the cone angle of diesel was wider than biodiesel and the penetration time of diesel tip was shorter than biodiesel at the same injection pressure. J. Gimeno et al. [14] made comparison with the spray characteristics of methanol-diesel and diesel, the results showed that diesel has more symmetrical spray shape and thinner spray boundary.

Researchers considered the influence of all aspects on the spray characteristics, and reached a remarkable depth by experiments and simulations. However, in the process of diesel spray impingement, many of researchers obtained experimental data that was not detailed enough. In this paper, firstly the visualization experiment system, its working process using constant volume combustion bomb and high-speed camera is introduced. The spray images are obtained by using the scattered light of small droplets. Secondly the grid division, model selection and parameter setting is given by using numerical simulation software (converge). The experiments and simulations of diesel spray impingement are carried out. The variation of spray radius and spray height in the process of diesel spray impingement is analyzed and the accuracy of the simulation is proved.

\section{Experiment}

\subsection{Experimental Apparatus and Procedures}

Figure 1 shows the laboratorial platform that constant volume combustion bomb visualization experimental system. This experiment uses a constant volume bomb visualization experimental system. The experimental equipment is as follows.

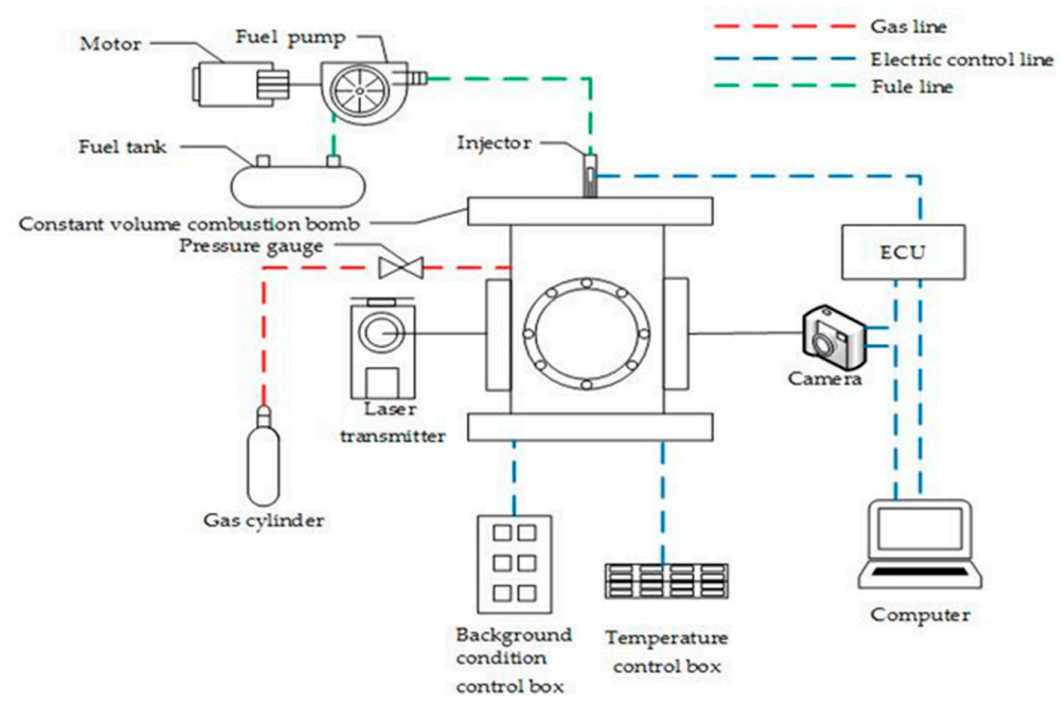

Figure 1. Constant volume combustion bomb visualization experimental system.

In the case of diesel spray, the heating tile system in the constant volume combustion bomb is used to heat up to the experimental condition. Through the motor, oil pump and fuel tank. The diesel oil is sent to the nozzle, controlling the oil pump, so that the fuel can meet the pressure of the experiment. 
Injection pressure, nozzle diameter and constant fuel injection was controlled by regulating the injector, in order to carry out the different parameters of diesel spray experiments. Temperature is adjusted by regulating the temperature control box. Observing the background condition control box and waiting for the temperature in the fixed volume combustion bomb to reach the required temperature. Through the joint action of the gas cylinder and the valve, bring nitrogen into the fixed volume combustion bomb until reaching the high concentration of nitrogen. When the temperature, pressure and nitrogen content in the bomb is fixed to the experimental requirements, the ECU sends a command to inject the fuel into the injector. At the same time, the ECU triggers the laser transmitter to emit a laser to trigger the camera to take a picture. The camera then sends the results back to the computer for storage, enabling a complete record of the diesel spray process [15-17].

\subsection{Experimental Conditions}

Experiments using high-speed camera system to study the diesel spray wall phenomenon, in order to obtain a better spray distribution, the experiment uses a single-hole nozzle. Specific conditions of the parameters shown in Table 1.

Table 1. Experimental conditions.

\begin{tabular}{cccc}
\hline Injection Conditions & Parameters & Environmental Conditions & Parameters \\
\hline Fuel & Diesel & Environmental Gas & Nitrogen \\
Spray mass $/ \mathrm{mg}$ & 25 & Ambient pressure $/ \mathrm{MPa}$ & 1 \\
Injection pressure/MPa & 40 & Ambient temperatures $/ \mathrm{K}$ & 723.15 \\
Injection time/ms & 4 & Hit the wall angle $\left./{ }^{\circ}\right)$ & 90 \\
Nozzle type & single hoe & Nozzle wall distance $/ \mathrm{mm}$ & 40 \\
Nozzle diameter $/ \mathrm{mm}$ & 0.26 & - & - \\
\hline
\end{tabular}

\section{Simulation}

\subsection{Spray-Wall Impingement Parameter Definitions}

Figure 2 describes the developments of post-wall spray, the spray height $(\mathrm{H})$ and spray radius $(\mathrm{R})$. The picture shows the vertical spray-wall parameters diagram. In the figure, the spray radius $\mathrm{R}$ is the penetration distance of the spray jet al.ong the wall direction after the collision wall; the spray wall height $\mathrm{H}$ is the penetration distance perpendicular to the wall; $\mathrm{L}$ is the distance from the injector to the wall surface; the parameters such as the diameter of diffusion and the height of the volume can be used to reflect the fuel volume of the wall and the volume of the air.

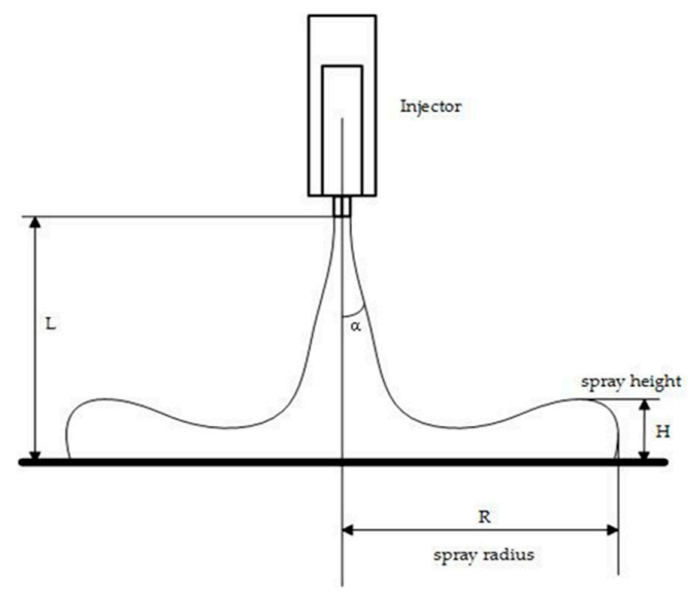

Figure 2. Spray-wall impingement parameter. 


\subsection{Spray-Wall Characteristics of the Empirical Calculation}

Wall run-through spray penetration experience calculation formula [18] for

$$
S=B \sqrt{t_{0}-t_{w}+L} B=(56.1-0.36 L-0.39 \varphi+0.0033 L \varphi)\left(\frac{1.5}{P_{a m b}}\right)^{0.25} \varphi=90-\theta
$$

where $S$ for the spray through the distance, including free spray and spray-wall collision; $B$ for the collision wall constant; $t_{0}$ for the start of injection time; $t_{W}$ for the wall hit the moment; $P_{a m b}$ for the environment back pressure; $L$ for the distance form nozzle to the wall; $\theta$ for the wall inclination (angle between the wall and the horizontal plane); $\varphi$ is the angle between the whole oil jet and the wall of the spray. This empirical formula calculation is suitable for evaluating single-jet spray penetration.

\subsection{Impingement oil Film Spread Modes}

Assuming that the thickness of the oil film is much smaller than the curvature radius of the wall and the characteristic length of the wall surface, the flow of the oil film is in a laminar state and its velocity direction is tangent to the wall surface. The size of the film changes linearly along the wall surfaces normal within the oil film. The velocity of air above the oil film is much higher than that of the oil film.

(1) Mass conservation equation. The main feature of the droplet impact wall process is the energy conversion based on the conservation of mass.

Droplets impinge on different walls, heat conduction and energy dissipation are different, after touching the wall of the droplet size distribution, normal and tangential velocity components are also different.

$$
\frac{\partial \rho h}{\partial t}+A\left[\rho\left(\overline{u_{1}}-v_{w}\right) h\right]=M
$$

where $\rho$ is the liquid density, $h$ is the oil film thickness, $A$ is the surface gradient operator, $\overline{u_{1}}$ is the average (absolute) velocity of the oil film, $v_{w}$ is the velocity on the wall, and $M$ is the mass source term per unit wall area.

(2) Momentum conservation equation. For the calculation of the oil film speed $\overline{u_{1}}$ based on the above assumptions, the following simplified momentum equation can be used to solve.

$$
\begin{aligned}
\rho_{1} h\left\{\frac{\partial \bar{u}_{1}}{\partial t}+\left[\left(\overline{u_{1}}-v_{w}\right) A\right] \overline{u_{1}}\right\}+h A p \\
=\tau_{w} t-\mu_{1}\left(\bar{T}_{1}\right) \frac{\overline{u_{1}-v_{W}}}{\frac{h}{2}}+P_{i m p}-\left(P_{i m p} \cdot n\right) n+M_{i m p}\left[\left(v_{w} \cdot n\right) n-\overline{u_{1}}\right] \\
+\delta p_{1} n+\rho_{1} h g
\end{aligned}
$$

where $p_{1}$ is the average pressure in the oil film; $\tau_{w}$ is the shear stress of the oil film surface; $\mathrm{n}$ is the unit normal vector, is the unit tangent vector in the same direction as $\left(\overline{u_{1}}-v_{w}\right) ; \mu_{1}$ is the dynamic viscosity of the liquid, is the average oil film temperature; $P_{i m p}$ is the impingement momentum source term and $M_{i m p}$ is the Wall quality source term.

\subsection{Calculation}

Converge software has automatic mesh using real-time meshing techniques and only needs to import the geometry. The calculated grid is shown in Figure 3.

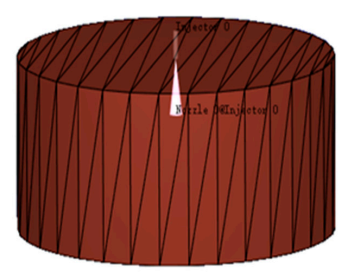

Figure 3. Computational grid. 
The grid is generated in real-time when it is calculated. It only needs to define the surface boundary and calculate the file settings. The experimental simulation prototype is a constant volume combustion bomb. The model is a cylinder with a bottom diameter of $80 \mathrm{~mm}$ and height of $40 \mathrm{~mm}$. In order to improve the accuracy of calculation and increase the speed of calculation at the same time, the base grid size is set to $(0.003,0.003,0.003)$ using CFD simulation software to simulate the diesel spray wall-in process of a constant volume combustion bomb. The initial conditions of physical model are shown in Table 2 and the $k-\varepsilon$ model parameters are shown in Table 3.

Table 2. Physical model.

\begin{tabular}{cc}
\hline Fuel injector model & LISA \\
Evaporation model & Frossling model \\
Collision model & O'Rourke droplet collision model \\
Injection temporal type & sequential \\
Turbulence model & Reynolds Averaged N-S,RNG k- $\varepsilon$ \\
\hline
\end{tabular}

Table 3. k- $\varepsilon$ model parameters.

\begin{tabular}{cccccc}
\hline $\mathrm{C}_{51}$ & $\mathrm{C}_{52}$ & $\mathrm{C}_{53}$ & $\mathrm{C}_{\boldsymbol{\mu}}$ & $\boldsymbol{\eta}_{\mathbf{0}}$ & $\boldsymbol{\beta}$ \\
\hline 1.42 & 1.68 & -1.0 & 0.0845 & 4.38 & 0.012 \\
\hline
\end{tabular}

\section{Results and Discussion}

\subsection{Spray Process}

Figures 4 and 5 shows photographs of the diesel oil wall shape developing over time. The spray mist head diverged before hitting the wall and the front of the body showed a more obvious diffusion phenomenon. A "mist" appeared on the edge of the sprayed head [19]. At $0.4 \mathrm{~ms}$, after the beginning of the injection, the obvious oil beam can already be seen. The diesel oil beam is sucked with the surrounding spray penetration length is $22.0 \mathrm{~mm}$, the spray radius is $3.33 \mathrm{~mm}$, and the oil beam angle is $6^{\circ}$. At $0.8 \mathrm{~ms}$ after the initial injection, the spray penetration length is $40 \mathrm{~mm}$, the spray radius is $9.3 \mathrm{~mm}$, and the oil beam angle is $6^{\circ}$. After two measurements, it was found that the cone angle of the oil beam do not change obviously. The results agree with the conclusion that the change of cone angle is small at high injection pressure. At this point, the phenomenon of diesel spray hitting the wall has occurred. The spray radius increases obviously in the spray stage after the measurement. Authors found that the injection pressure changes in spray cone angle were mainly affected by injection pressure [20] and air entrainment around the spray bundle. The injection pressure and the environment is unchanged in this test, so in the entire injector spray process the spray of diesel cone angle is unaltered significantly. Late in the fuel injection, due to the influence of gas on the spray oil bundle dominance, by the air entrainment effect, spray cone angle slightly increased. According to previous studies, the spray body was vertically challenged to form a circular wall expansion area, wall friction oil mist rise, the middle part of the sunken and the overall showing a "blanket" shape.

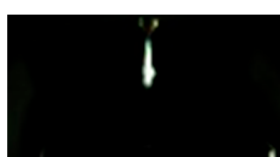

$0.4 \mathrm{~ms}$

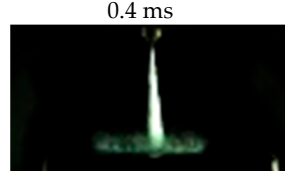

$2.0 \mathrm{~ms}$

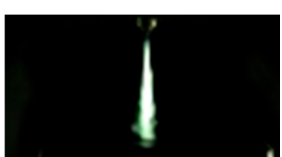

$0.8 \mathrm{~ms}$

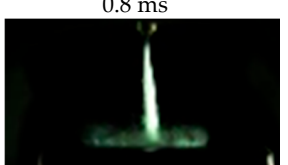

$2.4 \mathrm{~ms}$

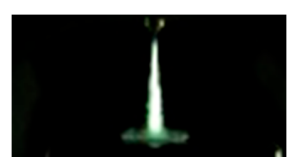

$1.2 \mathrm{~ms}$

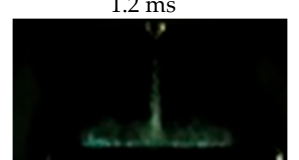

$2.8 \mathrm{~ms}$

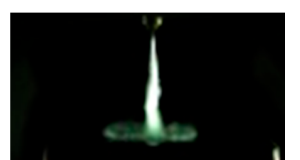

$1.6 \mathrm{~ms}$

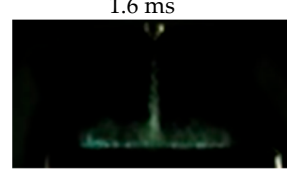

$3.2 \mathrm{~ms}$

Figure 4. Morphology evolution. 


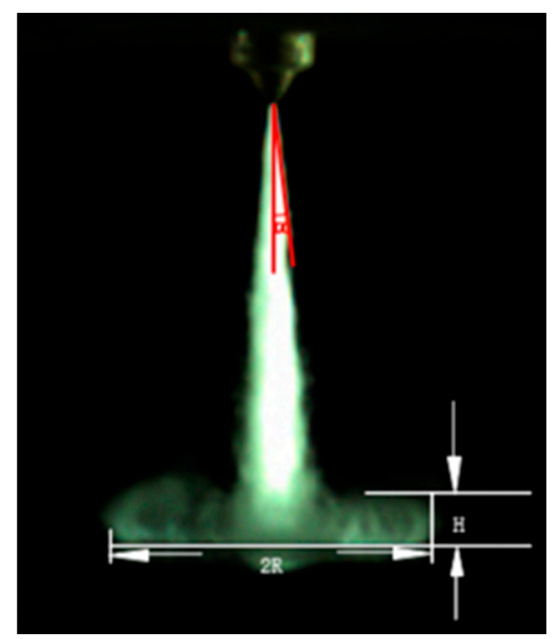

Figure 5. Experimental extraction of $\mathrm{R}, \mathrm{H}$, and $\alpha$.

The observation shows that there is obvious thinning area of oil mist around the outer wall of the diesel mist layer, and the area of the thin diesel mist becomes larger gradually with the passage of time. The area of the oil mist layer remains stable. There is the result of friction and air resistance received by wall-running oil bundles during wall expansion and intense entrainment with air. From diesel spray vertical wall test results, there is a clear characteristic that the fog injection contact wall and its development along the wall are symmetrical distribution. The wall is the center of the oil spray and the radial diffusion along the wall surface and the formation of oil film and phenomenon of oil mist wall climbing.

\subsection{Spray Height}

As can be seen from the Figure 6, the spray height is on the rise when the injection time is increasing.

At the time of $0.8 \mathrm{~ms}$, the image of the diesel spray impinging on the wall surface was observed. The beginning of the observed $\mathrm{H}$ is $3.33 \mathrm{~mm}$, increasing steadily from $0.8 \mathrm{~ms}$ to $1.4 \mathrm{~ms}$, and the increasing rate was $5.55 \mathrm{~m} / \mathrm{s}$. The results of the experimental results were close to the experimental results, and the mean error was $2.8 \%$.

In the period of $1.5 \mathrm{~ms}$ to $2.1 \mathrm{~ms}$, due to the strong entrainment of diesel spray and air, $\mathrm{H}$ increased slowly. On account of the injection pressure is high and the diesel atomization effect is good, that the particle size of the spray droplets is small, the interaction between the spray droplets group and the surrounding air is strong. The center of the gas spray has a greater momentum, the spray gas will be around the outer entrainment. After the wall hit the droplet was significantly broken, the occurrence of outward rebound or splash. Due to the influence of air resistance and friction, the rate of fortifying of spray height is decrease with the increase of spraying time. At this stage, the change of $\mathrm{H}$ is small, the growth rate is more and more slow, the average growth rate is $1.5 \mathrm{~m} / \mathrm{s}$, and the error of the calculation result and the experimental result is in the vicinity of $2.0 \%$.

After $2.2 \mathrm{~ms}$, spray height continued increasing from $8.4 \mathrm{~mm}$ to $10.2 \mathrm{~mm}$, the increasing rate is $2.9 \mathrm{~m} / \mathrm{s}$. The error between calculation and experiment is $3.2 \%$. Mainly due to the entrainment between the spray oil bundles and the environmental medium during the free movement, result in a part of oil mist was pushed by the droplet of the splashing wall but did not come into contact with the wall and the kinetic energy loss is small, resulting in a higher wall spray height. It is mainly due to the influence of air resistance and wall friction on the spray contact with the wall after diffusion and evaporation, which interferes the nearby gas molecules with it [21]. 

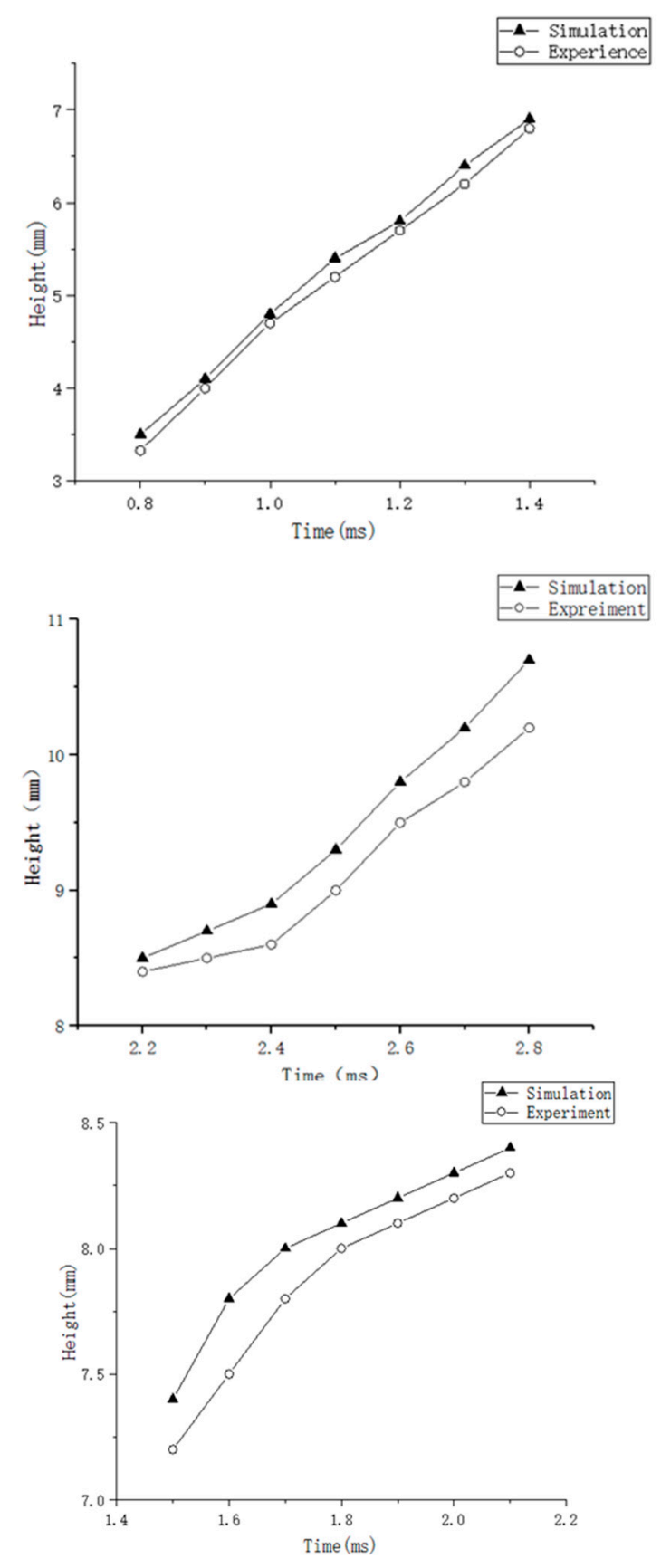

Figure 6. Spray height.

\subsection{Spray Radius}

Over time the particles collide with the wall after being hit by the atomizing particles and the amount of displacement along the wall is increasing, so that the spray radius increases at the later stage of the spray. Spray radius increases after hitting the wall, the droplet and the wall have a larger contact area, easy to quickly evaporate, spread, which also has a certain impact on the spray height. Diesel spray from the nozzle hole hit the wall. Diesel mist spread out along the wall and its forward is influenced by the surrounding air resistance and wall friction. Some dripping adhesions to the wall, which forms a peripheral spray edge.

As time goes by, the middle part is hollowed and the periphery rises. The droplet velocity, momentum and density in the main spray zone are larger. The wall jet area is located in the interior 
of the spray, and the droplet tangential velocity, momentum and concentration are large in this area. The earlier part of the oil drop coming into contact with the wall due to the loss of kinetic energy will be squeezed by the subsequent droplet of oil, resulting in a gradual increase in the radius of the spray and a turbulent mixing of the oil mist with the surrounding air in the peripheral area.

Figure 7 shows the change in spray radius. Compared to two curves can be seen, at the beginning of the spray, spray radius is the same, then the experimental value is always lower than the simulation value and the change tendency of the two curves are consistent. Mainly due to the spray volume absorb gas, causing air density, leading to the experimental value slightly smaller, does not take into account this in the simulation.

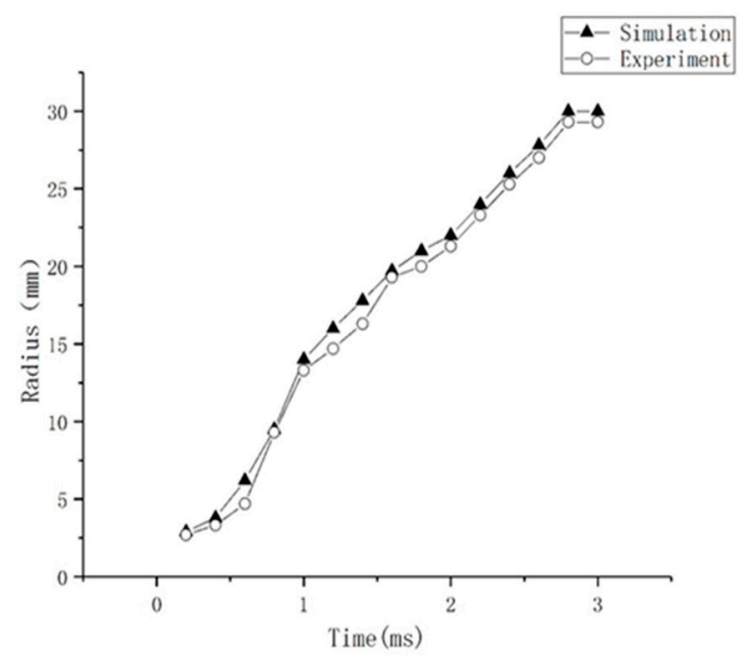

Figure 7. Spray radius.

\subsection{Spray Angle}

Figure 8 shows the variation of spray dispersion angle during the experiment, in the early stage of spray. The spray angle reaches a high value $\left(11^{\circ}\right)$ and then decreases to a stable angle $\left(4.5^{\circ}\right)$ which indicates a strong air entrainment. The spray cone angle is a global parameter and is subject to the ambient air density. Some scholars have pointed out that the droplet distribution of spray impingement clothing from the stagnation flow model was affected by the droplets before impingement $[22,23]$.

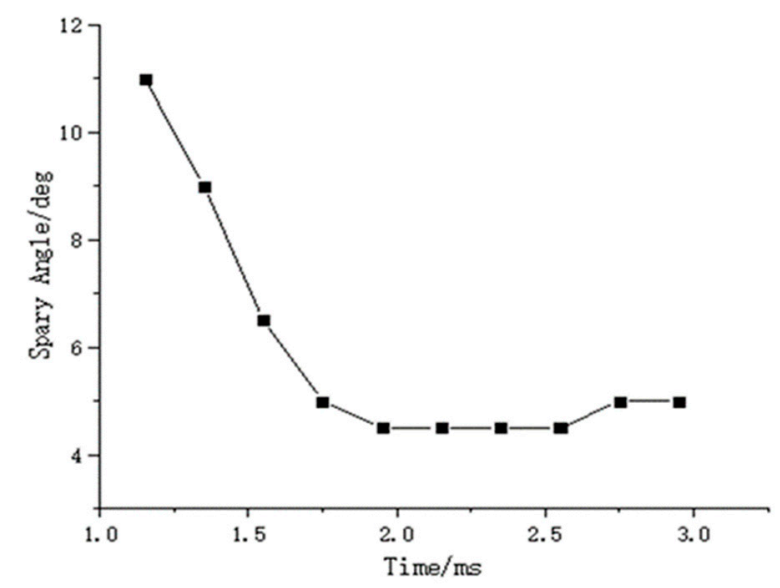

Figure 8. Spray Angle. 


\subsection{TKE Distribution}

Figure 9 shows the experimental images and the TKE distribution contours obtained by calculation. The experimental results make up for the lack of energy distribution in experimental images. The change of TKE over time reflects the dynamic change of turbulent kinetic energy and is an indicator of the direction of turbulence development. The result of TKE is basically consistent with the actual spray pattern. Calculation chart can be seen in the initial stages of spray hit a wall, in the center of the spray collision wall TKE value maximum. TKE is decrease, with the increase of the spray time. The energy is again hitting the wall and diffusing around. The calculation equation of TKE is:

$$
k=\frac{3}{2} u_{i}^{2} I^{2}
$$

where $k$ is the turbulent kinetic energy and $I$ is the turbulence intensity. The turbulence intensity is usually set to a value between 0.01 and 0.10 . Mainly due to the simplified model of spray evaporation, the simulation results are somewhat similar to the experiment. However, this model provides a good background for interpreting experimental results and provided conditions for other directions of study. When the environmental pressure is constant, the oil film quality increases with the increase of the injection pressure, and the oil film quality is almost stable for a period of time [24,25]

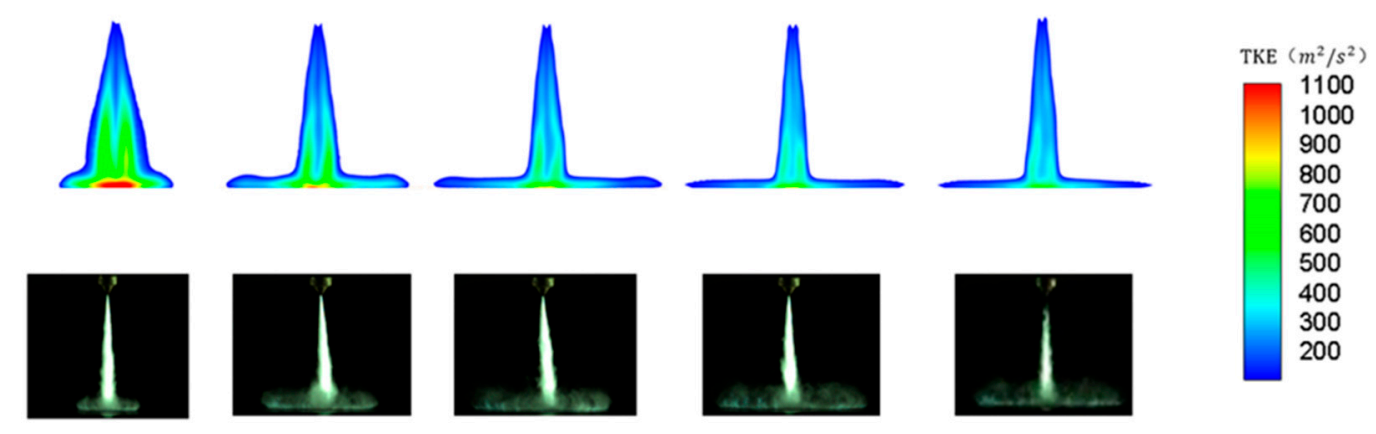

Figure 9. Experimental photos and TKE distribution.

\section{Conclusions}

In this paper, the development process of diesel spray impingement is studied. The spray condition is $25 \mathrm{mg}$ for fixed injection oil, $40 \mathrm{MPa}$ for injection pressure, $40 \mathrm{~mm}$ for the wall distance and $0.26 \mathrm{~mm}$ for the nozzle diameter. The spray recording is made by using high-speed camera visualization technology in the nitrogen environment in the constant volume combustion bomb. It was simulated by software. The following conclusions can be drawn:

(1) The spray height and spray radius increased with the increase of injection time. Oil film thickness gradually increased. At injection time of $2.8 \mathrm{~ms}$, the spray radius and spray height reached the maximum values of $29.3 \mathrm{~mm}$ and $10.2 \mathrm{~mm}$.

(2) The spray height changes in three stages from spray contact with the wall. The spray height increases firstly, then decreases, finally rises, and the whole shows an upward trend. The average error between the calculation and experiment of spray height is $2.7 \%$, which verifies the feasibility of the calculation model.

Acknowledgments: This work was supported by Beijing Municipal Natural Science Foundation (KZ201510016019), State Key Laboratory of Engines, Tianjin University (K2017-07), the National Nature Science Foundation of China (51576140, 91641111) and Science and Technology Project of Beijing Education Commission (KM201510016011).

Author Contributions: Yongfeng Liu proposed the idea of visualization experiment combined with the simulation experiment. Fang Wang designed the experiments. Shengzhuo Yao, Xingyu Liang performed the experiments and analyzed the data. Zhijun Li accomplished the numerical simulation. Yongfeng Liu and Qi Xiang wrote the paper.

Conflicts of Interest: The authors declare no conflict of interest. 


\section{References}

1. Zhu, X.; Zhao, L.; Zhao, Z.; Ahuja, N.; Naber, J.; Lee, S.Y. An Experimental Study of Diesel Spray Impingement on a Flat Plate: Effects of Injection Conditions. In Proceedings of the Ofilass-European 2017, 28th Conference on Liquid Atomization and Spray Systems, Valencia, Spain, 6-8 September 2017.

2. Wang, Y.; Yang, S.; Li, B.; Zhang, Z.; Xu, J. Experiment on impingement spray characteristics of multi-hole injector in gasoline direct injection engine. J. Jiangsu Univ. 2013, 34, 390-394.

3. Wei, M.R.; Liu, F.; Wen, H.; Liu, Y.C.; Zhang, Y.S. Numerical simulation and experimental research of DME spray wall-impingement. Chin. Intern. Combust. Eng. Eng. 2009, 78, 408-418.

4. Kong, H.; Luo, H.; Zhang, Q.; Keiya, N. Experimental research on spray and impingement characteristics of direct injection gasoline engine. J. Yanshan Univ. 2017, 41, 13-20.

5. Liu, Y.; Jia, X.; Pei, P.; Yong, L.U.; Li, Y.I.; Yan, S. Simulation and Experiment for Oxygen-enriched Combustion Engine Using Liquid Oxygen to Solidify $\mathrm{CO}_{2}$. Chin. J. Mech. Eng. 2016, 29, 188-194. [CrossRef]

6. Mao, L.W.; Su, W.H.; Pei, Y.Q. Study on fuel distribution of diesel spray flat wall impingements. Neiranji Gongcheng/Chin. Intern. Combust. Eng. Eng. 2016, 37, 98-104.

7. Mao, L.; Su, W.; Pei, Y. Quantitative study of impingement characteristics of diesel spray. J. Combust. Sci. Technol. 2015, 21, 521-529.

8. Wang, J.G.; Wang, X.R.; Liu, J.T.; Wang, X. Effect of Injection Pressure and Ambient Pressure on Diesel Spray Characteristics. Veh. Power Technol. 2017, 2, 38-43.

9. Du, W.; Lou, J.; Yan, Y.; Bao, W.; Liu, F. Effects of Injection Pressure on Diesel Sprays in Constant Injection Mass Condition. Appl. Therm. Eng. 2017, 121, 234-241. [CrossRef]

10. Zama, Y.; Odawara, Y.; Furuhata, T. Experimental investigation on velocity inside a diesel spray after impingement on a wall. Fuel 2017, 203, 757-763. [CrossRef]

11. Payri, R.; Salvador, F.J.; Morena, J.D.L.; Pagano, V. Experimental investigation of the effect of orifices inclination angle in multihole diesel injector nozzles. Part 2-Spray characteristics. Fuel 2018, 213, 215-221. [CrossRef]

12. Song, E.; Li, Y.; Dong, Q.; Fan, L.; Yao, C.; Yang, L. Experimental research on the effect of shock wave on the evolution of high-pressure diesel spray. Exp. Therm. Fluid Sci. 2018, 93, 235-241. [CrossRef]

13. Yu, S.; Yin, B.; Jia, H.; Wen, S.; Li, X.; Yu, J. Theoretical and experimental comparison of internal flow and spray characteristics between diesel and biodiesel. Fuel 2017, 208, 20-29. [CrossRef]

14. Payri, R.; Gimeno, J.; Bracho, G.; Vaquerizo, D. Study of liquid and vapor phase behavior on Diesel sprays for heavy duty engine nozzles. Appl. Therm. Eng. 2016, 107, 365-378. [CrossRef]

15. Roy, S.P.; Cai, J.; Modest, M.F. Development of a multiphase photon Monte Carlo method for spray combustion and its application in high-pressure conditions. Int. J. Heat Mass Transfer 2017, 115, 453-466. [CrossRef]

16. Algayyim, M.S.J.; Wandel, A.P.; Yusaf, T.; Hamawand, I. The impact of n-butanol and iso-butanol as components of butanol-acetone (BA) mixture-diesel blend on spray, combustion characteristics, engine performance and emission in direct injection diesel engine. Energy 2017, 140, 1074-1086. [CrossRef]

17. Pastor, J.V.; García-Oliver, J.M.; García, A.; Pinotti, M. Effect of laser induced plasma ignition timing and location on Diesel spray combustion. Energy Convers. Manag. 2017, 133, 41-55. [CrossRef]

18. Li, F.; Yi, B.; Fu, W.; Song, L.; Liu, T.; Hu, H.; Lin, Q.Z. Experimental study on spray characteristics of long-chain alcohol-diesel fuels in a constant volume chamber. J. Energy Inst. 2018, in press. [CrossRef]

19. Wang, Y.; Bo, L.; Li, Y.; Feng, C. Experiment and simulation of spray impingement for gasoline direct injector. J. Jiangsu Univ. 2011, 32, 410-415.

20. Liu, J.; Bao, G.; Du, H.; Wang, Z.; Xu, B. Experimental study on spray and impingement characteristics of acidic oil biodiesel. J. Chin. Agric. Mech. 2016, 37, 161-165. [CrossRef]

21. Pandal, A.; García-Oliver, J.M.; Novella, R.; Pastor, J.M. A computational analysis of local flow for reacting Diesel sprays by means of an Eulerian CFD model. Int. J. Multiph. Flow 2018, 99, 257-272. [CrossRef]

22. Payri, R.; Viera, J.P.; Wang, H.; Malbec, L.M. Velocity field analysis of the high density, high pressure diesel spray. Int. J. Multiph. Flow 2016, 80, 69-78. [CrossRef]

23. Yu, H.; Liang, X.; Shu, G.; Wang, Y.; Zhang, H. Experimental investigation on spray-wall impingement characteristics of $n$-butanol/diesel blended fuels. Fuel 2016, 182, 248-258. [CrossRef] 
24. Wang, X.; Han, Z.; Su, W. Numerical study of the impact on high-pressure and evaporating spray behavior of nozzle cavitation at typical diesel engine conditions. Int. Commun. Heat Mass Transfer 2017, 81, 175-182. [CrossRef]

25. Detection, G.; Isolation, V. Reduced kinetic mechanisms of diesel fuel surrogate for engine CFD simulations. Combust. Flame 2015, 162, 3991-4007. 